\section{Nasal intermittent positive pressure ventilation in the treatment of respiratory failure in obstructive sleep apnoea}

\author{
Julia Bott, Simon V Baudouin, \\ John Moxham
}

\begin{abstract}
Severe respiratory failure in a patient with obstructive sleep apnoea was treated successfully with nasal intermittent positive pressure ventilation.
\end{abstract}

Nasal intermittent positive pressure ventilation is a non-invasive method of respiratory support originally developed for the treatment of chest wall and neuromuscular disorders. ${ }^{12}$ Recent studies suggest that this technique may be applicable to a broader range of respiratory problems, including respiratory failure arising from chronic obstructive airways disease. $^{34}$

Most patients with obstructive sleep apnoea respond to treatment with continuous positive airways pressure. $^{56}$ Occasionally patients present with such severe respiratory failure that endotracheal intubation and conventional intermittent positive pressure ventilation are needed. We describe a patient with obstructive sleep apnoea, presenting with severe respiratory failure, who was successfully managed with nasal intermittent positive pressure ventilation.

\section{Case report}

FIRST ADMISSION

A 44 year old obese $(152 \mathrm{~kg})$ publican was admitted in July 1988 with a four month history of increasing daytime somnolence and lethargy, morning headaches, nocturnal snoring, and intermittent episodes of loss of consciousness. He was a heavy smoker ( 80 cigarettes a day for 25 years) but had previously been well with no respiratory symptoms, and was not taking any medication. The patient reported that he drank one bottle of wine a month. He had visited his general practitioner in 1987 for disturbed sleep due to "missed heartbeats," but a 24 hour electrocardiogram tape had shown no abnormalities.
On examination he was deeply cyanosed and drowsy but rousable to pain, with a respiratory rate of $6 / \mathrm{min}$. He had pronounced peripheral oedema and a raised jugular venous pressure. In other respects the respiratory and cardiovascular systems were normal, as was his facial appearance. The chest radiograph showed a large heart with clear lung fields; an electrocardiogram was normal, and the haemoglobin concentration was $17 \cdot 8 \mathrm{~g} / \mathrm{dl}$. Arterial blood gases taken when he was breathing air showed an arterial oxygen tension $\left(\mathrm{PaO}_{2}\right)$ of $3.3 \mathrm{kPa}$, an arterial carbon dioxide tension $\left(\mathrm{PaCO}_{2}\right)$ of $9.7 \mathrm{kPa}$, and a $\mathrm{pH}$ of $7 \cdot 19$.

A clinical diagnosis of severe respiratory failure due to obstructive sleep apnoea was made. The patient deteriorated despite a short trial of doxapram. He was therefore intubated and intermittent positive pressure ventilation was started. $\mathrm{He}$ had several complications associated with this, including episodes of lobar collapse due to retained secretions, recurrent pneumonia, and problems with the tracheostomy. He required repeated bronchoscopies. The patient remained in the intensive care unit for a month and was finally weaned with the help of continuous positive airways pressure, delivered via a $\mathrm{T}$ piece.

Clinical observation and overnight pulse oximetry confirmed the diagnosis of obstructive sleep apnoea. When the tracheostomy was spigoted at night there were frequent episodes of severe dips in oxygen saturation $\left(\mathrm{SaO}_{2}\right)$, which for at least half of the night was below $85 \%$, the mean minimum of $65 \%$ accounting for $5 \%$ of the night; these dips coincided with observed episodes of obstructive apnoea and were greatly reduced when the tracheostomy was open. Nocturnal continuous positive airways pressure was continued until the patient had lost $37 \mathrm{~kg}$ (weight $115 \mathrm{~kg}$ ); at this time overnight pulse oximetry showed a great improvement in nocturnal $\mathrm{SaO}_{2}$ with the tracheostomy closed. In view of these findings and the patient's unwillingness to continue with mechanical assistance, he was discharged without domiciliary continuous positive airways pressure. Before discharge daytime arterial blood gas values when he was breathing air were: $\mathrm{PaO}_{2} 10 \cdot 1 \mathrm{kPa}, \mathrm{PaCO}_{2} 4.7 \mathrm{kPa}$, and pH 7.42; spirometric values were: forced expiratory volume in one second $\left(\mathrm{FEV}_{1}\right) 2 \cdot 3$ (predicted 3.6 ) litres, forced vital capacity (FVC) 3.7 (pred 4.8) 1, and peak expiratory flow (PEF) 315 (pred 575) $1 / \mathrm{min}$, with no reversibility after $400 \mu \mathrm{g}$ inhaled salbutamol. The duration of this first admission was 3 months.

Outpatient management was successful initially. The patient stopped smoking but his weight gradually increased to $132 \mathrm{~kg}$. An admission was arranged to check his overnight oxygen saturation, but he defaulted from follow up. 


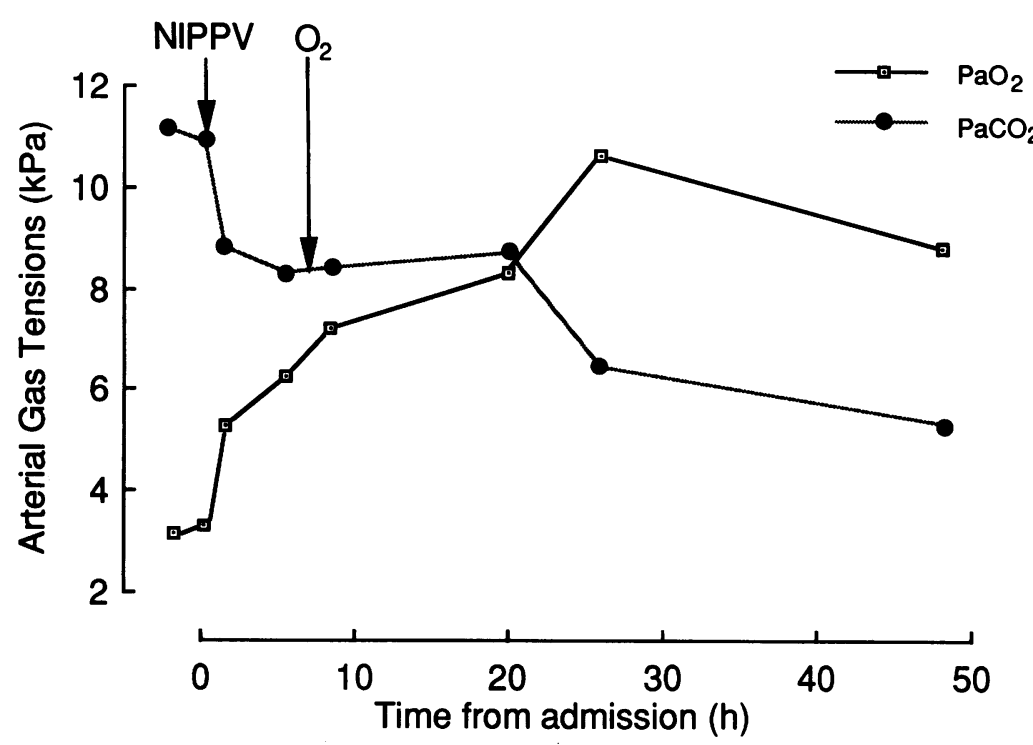

Changes in arterial blood gases after admission (hours). Nasal intermittent positive pressure ventilation (NIPPV) was started and 1 l/min oxygen was entrained into the nasal mask at the points indicated.

\section{SECOND ADMISSION}

In December 1989 the patient was brought to the admissions ward by his wife, who gave a history very similar to that obtained at the first admission. Clinical assessment confirmed severe respiratory failure and arterial blood gas values while he was breathing air were: $\mathrm{PaO}_{2} 3 \cdot 2$ $\mathrm{kPa}, \mathrm{PaCO}_{2} 11 \cdot 2 \mathrm{kPa}$, and $\mathrm{pH} 7 \cdot 24$.

The patient was transferred to the intensive care unit for a trial of nasal intermittent positive pressure ventilation, which was started immediately with a Lifecare PLV 100 (Medicaid). One hour after starting treatment his arterial blood gases and clinical state had improved $\left(\mathrm{PaO}_{2} 5.4 \mathrm{kPa}, \mathrm{PaCO}_{2} 8.9 \mathrm{kPa}\right.$, and $\left.\mathrm{pH} 7.36\right)$. Oxygen $(21 / \mathrm{min})$ was then entrained into the nasal mask, and improvement continued (figure). He was transferred to a general medical ward after three days, where nasal intermittent positive pressure ventilation was discontinued and nocturnal continuous positive airways pressure (Sleepeasy 11, Medicaid) commenced. Spirometry at this time showed FEV 1.35 1, FVC 4.51 and PEFR $365 \mathrm{l} / \mathrm{min}$. Overnight pulse oximetry was performed with and without continuous positive airways pressure. He was noted to have significant periods of profound oxygen desaturation, which were abolished with a continuous positive airway pressure of $12.5 \mathrm{~cm} \mathrm{H}_{2} \mathrm{O}$. He was discharged home with nocturnal nasal continuous positive airways pressure on day 13.

The patient was well at follow up with a weight of $113 \mathrm{~kg}, \mathrm{PaO}_{2} 9.54 \mathrm{kPa}, \mathrm{PaCO}_{2} 5.09 \mathrm{kPa}$, and pH 7.44; FEV 12.41 , FVC 4.51 , and PEF $365 \mathrm{l} / \mathrm{min}$. His neck circumference was $49 \mathrm{~cm}$.

\section{Discussion}

We describe the successful use of nasal intermittent positive pressure ventilation in the treatment of acute respiratory failure due to obstructive sleep apnoea. This technique has several clear advantages over conventional intermittent positive pressure ventilation and many of these are illustrated by the contrasting admissions of our patient. Intermittent positive pressure ventilation requires some form of endotracheal intubation and is associated with several complications, including nosocomial infections and weaning difficulties. ${ }^{7}$ If ventilation is prolonged a tracheostomy is needed and this is associated with both short and long term problems. ${ }^{8}$ Some of these complications occurred during our patient's first admission and led to the prolonged length of stay (three months) in hospital.

In contrast, nasal intermittent positive pressure ventilation is relatively free of problems provided that it can be tolerated. Possibly the hypoventilation and $\mathrm{CO}_{2}$ narcosis in our patient helped us to establish nasal intermittent positive pressure ventilation as we have found greater difficulties in starting nasal intermittent positive pressure ventilation in severely breathless patients with high respiratory rates. In patients for whom intermittent positive pressure ventilation is otherwise indicated a trial of nasal intermittent positive pressure ventilation should be performed only in a critical care setting with the facility to institute conventional ventilation.

By avoiding the complications associated with conventional ventilation the length of stay and therefore cost of admission were greatly reduced. Although the cost $(£ 3000-£, 6000)$ of a nasal ventilator may seem high, it may be cost effective when the shorter length of stay and the avoidance of high cost treatment in the intensive care unit are taken into account. The purchase of such equipment might therefore be justified, even if used only occasionally. Current clinical trials of nasal intermittent positive pressure ventilation should be able to address these issues.

1 Branthwaite MA. Nasal intermittent positive pressure ventilation. Care of the Critically Ill 1989;5:139-41.

2 Ellis ER, Bye PTP, Bruderer JW, Sullivan CE. Treatment of respiratory failure during sleep in patients with neuromuscular disease. Positive pressure ventilation through a nose mask. Am Rev Respir Dis 1987;135:148-52.

3 Carroll N, Branthwaite MA. Control of nocturnal hypoventilation by nasal intermittent positive pressure ventilation. Thorax 1988;43:349-53.

4 Elliott MW, Steven MH, Phillips GD, Branthwaite MA Non-invasive mechanical ventilation for acute respiratory failure. $B M J$ 1990;300:358-60.

5 Sullivan CE, Berthon-Jones M, Issa FG, Eves L. Reversal of obstructive sleep apnoea by continuous positive airway pressure applied through the nares. Lancet $1981 ; \mathrm{i}: 862-5$.

6 Lombard RM Jr, Zwillich CW. Medical therapy of obstructive sleep apnoea. Med Clin North Am 1985;69:1317-35.

7 Zwillich CW, Pierson DJ, Creagh CE, Sutton FD, Schatz E Pety TL. Complications of assisted ventilation. A prospective study of 354 consecutive episodes. Am J Med 1974;57:161-70.

8 Heffner JE, Miller KS, Sahn SA. Tracheostomy in the intensive care unit. Part 2: Complications. Chest 1986; 90:430-6. 